\title{
Family Organization in the Care of Pediatric Heart Transplant Patients: The Genogram as an Investigative Tool
}

\author{
Silvania Braga Ribeiro, Angela Maria Alves e Souza, Ana Ruth Macêdo Monteiro, \\ Kiarelle Lourenço Penaforte, Sarah Maria de Sousa Feitoza, Virna Ribeiro Feitosa Cestari, \\ Flávia Paula Magalhães Monteiro, Maria Gyslane Vasconcelos Sobral, \\ Samila Torquato Araújo, Máguida Gomes da Silva, Mona Lisa Menezes Bruno, \\ Islene Victor Barbosa, Isabelle Barbosa Pontes
}

Department of Nursing, Universidade de Fortaleza, Fortaleza, Brazil

Email: sarahfeitoza22@yahoo.com.br

Received 3 September 2015; accepted 3 November 2015; published 6 November 2015

Copyright (C) 2015 by authors and Scientific Research Publishing Inc.

This work is licensed under the Creative Commons Attribution International License (CC BY).

http://creativecommons.org/licenses/by/4.0/

\begin{abstract}
This study aimed to describe structure, functionality and development of pediatric heart transplant families, from the understanding of the experienced chronic condition. A descriptive, exploratory study using a qualitative approach was developed in a hospital situated in a city of Northeast Brazil, in 2012. The study was conducted with three families, using the Calgary Family Assessment Model (CFAM). In addition to the genogram, an analysis of the children's/adolescents' family members was conducted at the time of interview. Two families were binuclear families and one was mononuclear. From the evaluation, it was possible to determine the care and support network of children and adolescents with heart transplants, as well as some difficulties faced by the investigated families. Nurses are important in this family context since the visualization of the family genogram can generate a change in the nursing care to each family.
\end{abstract}

\section{Keywords}

Chronic Disease, Heart Transplant, Child, Family, Nursing Assessment

\section{Introduction}

Conceptions on family and children have undergone transformations over time, being influenced in each historical period by advances in knowledge and the involvement of multiple agents and segments of society. Chronic 
diseases also contribute to changes in family dynamics, especially if there is the need of hospitalization [1]. Chronic conditions in childhood are those of biological, psychological or cognitive bases, which last or have the potential to last a year and that produce sequelae [2].

There has been an increase of chronic conditions in childhood, especially of those related to illness. With respect to chronic heart disease, an increased rate of survival and consequently the demand for complex care has been observed. Chronic heart disease is a continuous threat, not only to the patient's life but also for those who are close to them, since this condition affects their lives as a whole, dramatically changing their daily routine [3].

In this context, chronic heart failure stands out as a syndrome characterized by the reduced efficiency of the heart, resulting from hemodynamic and neuro-hormonal responses, where the use of technology becomes an important management strategy. For children with a survival expectancy of less than two years, and after exhausting conservative therapies, heart transplants are recommended [4].

Considering the complexity involved in heart transplants, the need for nursing care to the child and the family is emphasized, directing them in the direction of quality of life [5]. For patients and their families, the survival of heart transplants is associated with chronic disease management, including the use of immunosuppressive drugs, clinical visits, stress, risk of graft loss and other medical complications [6].

Family is the primary caregiver of its members and its importance has been related to increased life expectancy and health promotion. Thus, family-centered care has enabled benefits for planning the actions of health professionals [7] [8]. Based on this, theoretical nursing development has been showing the need to include family more and more in the context of nursing care, contributing to family-centered care principles being adopted [9].

Considering the impact caused by the heart transplantation process, the use of the Calgary Family Assessment Model (CFAM) enables a larger view of the family system, which includes its internal and external relations, strengths and weaknesses [10]. The use of this model allows the nurse to meet the family in their context and identify their needs, as well as alternatives of specific care for their condition [11].

In the development of this study, we decided on the use of genograms, which has been a valuable instrument for obtaining relevant information needed for understanding family processes and its relations with the community, particularly in pediatric nursing which requires details for care planning interventions involving caregivers [12].

Given this, the question arose: what is the influence of the family on the care of children who have undergone a heart transplant? Due to the applicability of these assessment tools and dynamics of the structure and family relationships, this study aims to describe the structure, function and development of families of pediatric heart transplant patients, based on understanding their chronic condition.

\section{Methods}

\section{Study Design and Participants}

A descriptive study with a qualitative approach, based on the theoretical framework of CFAM and its three main categories: structural (integrates aspects of the family structure, integrating aspects related to its internal external and context structure), development (assessment enables the understanding of exclusive phenomena of the family associated with its growth and evolutional path at a functional, structural and interactional level) and functional (features the way in which family members interact with each other), each one these dimensions integrates many categories and sub-categories that enable a systems assessment of the family using a dynamic and continuous perspective [13]. The research was developed in a tertiary public hospital network, located in a city of Northeast Brazil. The chosen institution is a reference center in cardiopulmonary disease care, specialized in adult and child heart transplants.

Based on these data, non-probalistic convenience sampling was calculated with were three families of children who had undergone a heart transplant in the Pediatric Cardiology unit. For data collection, individual interviews based on a semi-structured instrument created by the authors were conducted with the subjects of this study. In order to outline the CFAM categories, we used a genogram (a representative diagram of the family group) in order to assist in the assessment, planning, and family intervention, and to allow knowing what members constitute the family. In order to assist in the assessment, planning and family intervention, and for determining which members constitute the family. For the construction of the genogram, notes were taken in chronological order, meaning from the oldest to the youngest, and from left to right in each generation. Its elaboration 
occurs via graphic signs, standard symbols, and dashed lines which link families to important events in their lives represented in a legend.

The genogram was designed with active participation of the family, with freedom for discussion and considerations on the charts, in addition to specific guidance about each experienced situation. Methodologically, a blank sheet of paper was used on which demographic data (age, gender), health (disease which affects and/or has affected the family and its members), education level, critical events experienced and family backgroundwere included. Three generations were included for each family studied (Figure 1). One family member was defined as the Index Person (IP) for designing the organization of family genograms [13]. The data were analyzed based on the literature and is the type description.

The project was approved by the Research Ethics Committee of the Federal University of Ceará and locus of the study, conforming to Protocol 885/12. To protect the anonymity of the participants, we used pseudonyms of angels for the children/adolescents who had heart transplants and for the family members.

\section{Results}

Three genograms were designed to represent the families of children/adolescents who underwent heart transplants, allowing for the understanding of their internal and external structures, as described below.

\subsection{Family 1 Interview}

The structural assessment of family 1 identified this was a binuclear family composed of Lirio and Adonis. Lirio is 37 years old; she is a housewife and lives with her husband and two children. Adonis is 34 and works at a metalworking company. They have two children, Gabriel and Rosa. Gabriel is 11 years old and he is in the 5th grade (of elementary school). Rosa is six years old and she is in the first grade (of elementary school).

In analyzing Gabriel's family background, his maternal grandmother is 64 years old, retired, hypertensive, and widowed for the second time. Her first husband was a mason/bricklayer, an alcoholic and died in 1968 of liver cirrhosis. They had eight children: the eldest, a 50-year-old son; after him, a 49-year-old son who is a mason/bricklayer; then a 48-year-old daughter who is an administrator; a 46-year-old daughter who works in a school; a 45-year-old daughter, retired, who had meningitis at the age of five, and went deaf due to the illness;

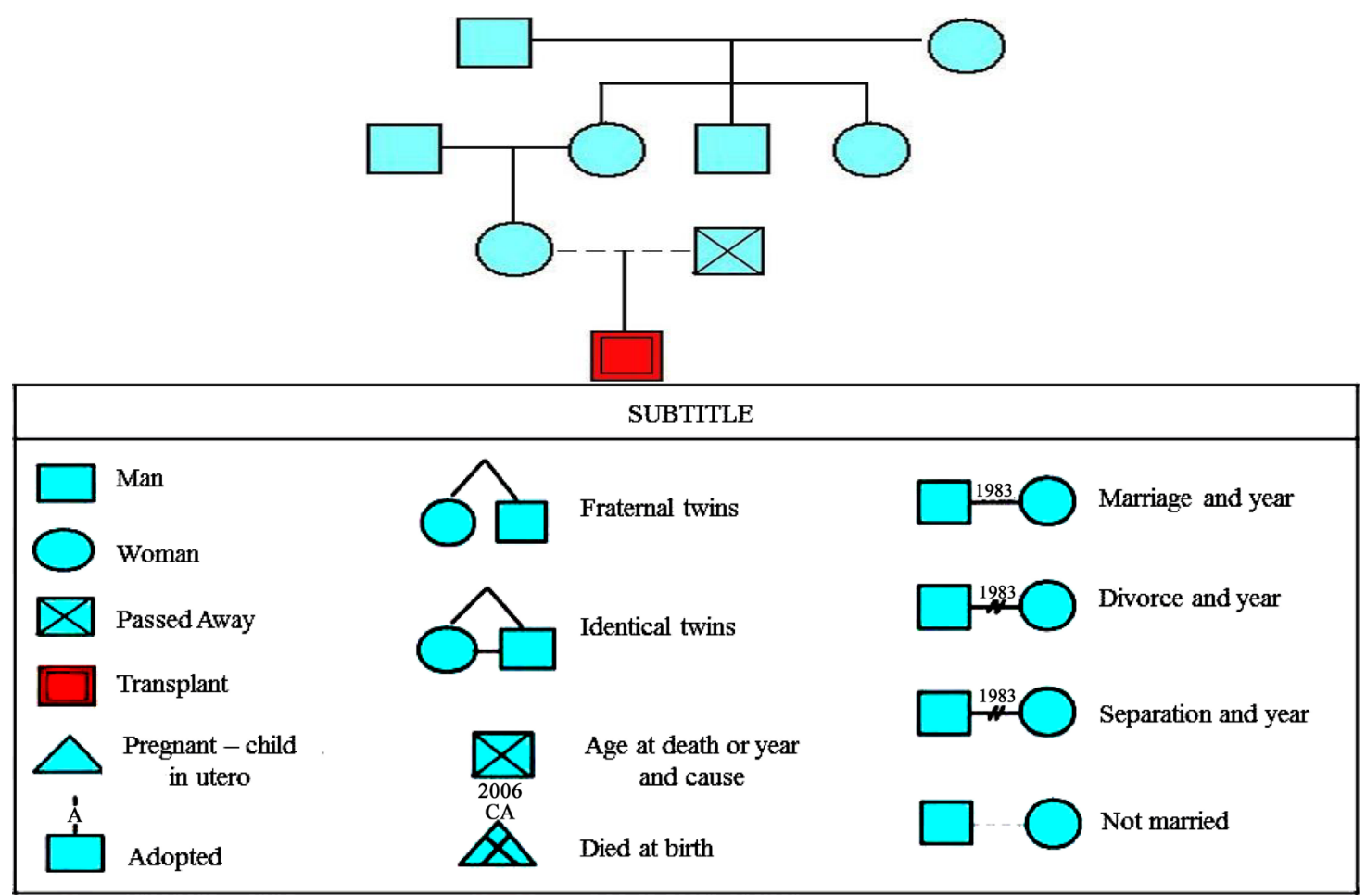

Figure 1. Model and subtitle of genogram. Fortaleza, Ceará, Brazil, 2015. 
the sixth (child) a daughter who died at the age of 12, was hit by a car; a 38-year-old son who is a taxi driver; and the eighth child, a daughter, the youngest of the family is Gabriel's mother. Her second husband died from diabetic complications. From him she miscarried a girl (Figure 2).

In relation to the development category, it was identified that Gabriel was born in January 31, 2001 and had a transplant in August 27, 2007, at six years and six months, with the medical diagnosis of Tricuspid Atresia II congenital heart disease. He underwent some heart surgeries and had a pacemaker implanted, a last resource due to ventricular dysfunction, indicating the transplant.

The functional category assessment identified that Lirio plays the role of main caregiver. The mother's accounts revealed that the family organization has generated intense physical and emotional exhaustion in caring for the child with chronic conditions experienced at different times by family.

When asked about the quality of life after the heart transplant, she reported that the relationship among the family improved. Troubled interpersonal interactions were being eased as Gabriel was adapting to the new situation. During the meetings with Lirio, she demonstrated having a strong relationship with God.

\subsection{Family 2 Interview}

The structural assessment revealed that the family is the binuclear type, consisting of Iris and Amaranto. Iris is 35 years old; she is a housewife and illiterate. She is married for the second time. She had three daughters from her first marriage; her first husband died from Chagas disease (or American trypanosomiasis). Her oldest daughter died in 2012, at 14 years old, from a dilated cardiomyopathy transplant. Her second child is 13-year-old Mihr, and the third daughter is 11 . Amaranto is 27 years old and works as a bricklayer; from this second marriage she had two daughters; the first child is seven and the second is three.

Her maternal grandmother died in 1985 of a heart attack, she had an "enlarged heart", her grandfather is 75 years, retired and residing at his daughter's house. She has four sisters and one brother. The paternal grandparents were alive and they have two daughters and one son, but two sons died of heart problems (Figure 3).

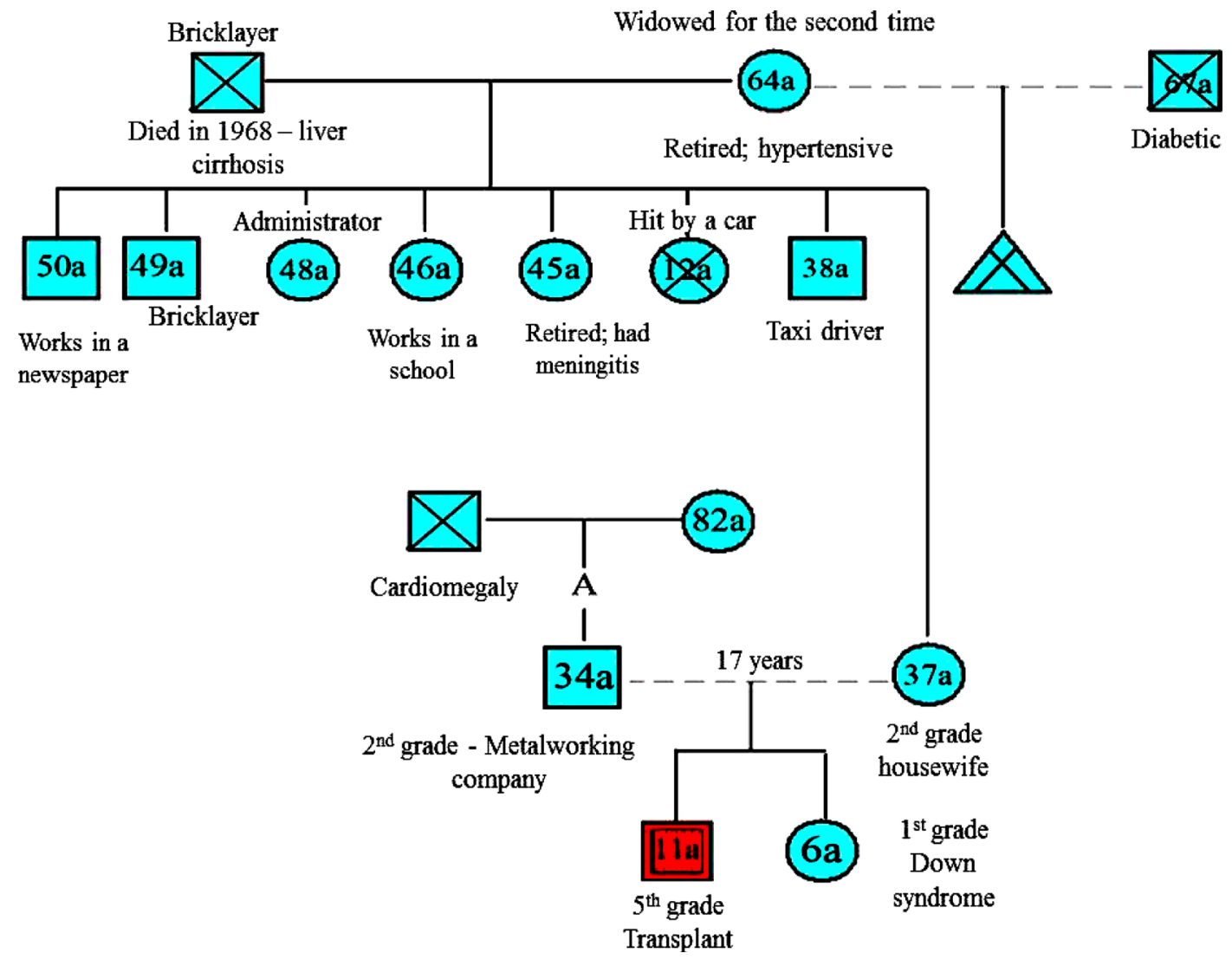

Figure 2. Genogram designed for Lirio’s family. Fortaleza, Ceará, Brazil, 2015. 


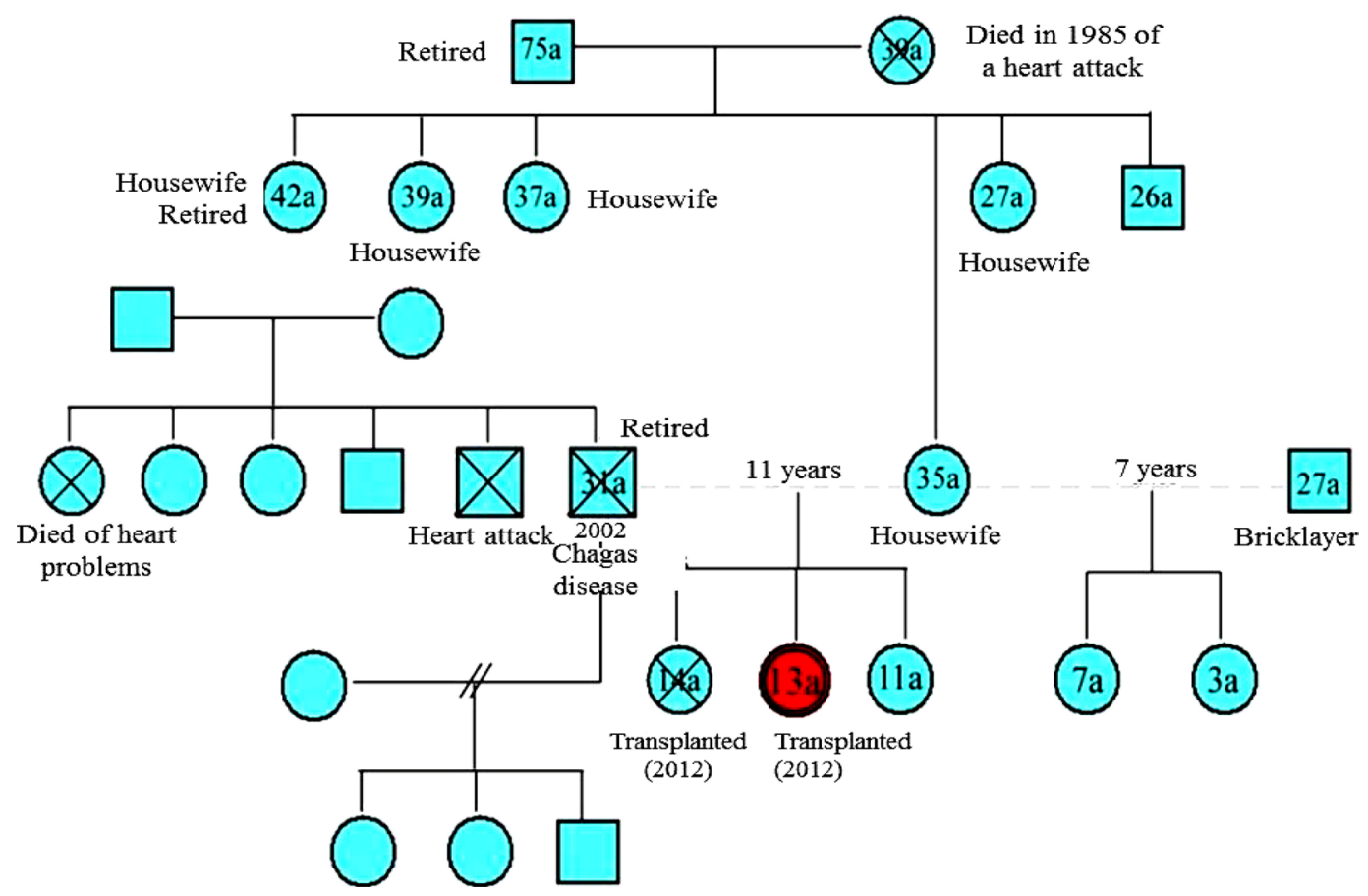

Figure 3. Genogram designed for Azaleia family. Fortaleza, Ceará, Brazil, 2015.

The developmental category identified that Mihr was born in August 8, 1999. She had a transplant on July 12, 2011 and underwent a re-transplant on July 30, 2012. Her initial diagnosis at 13 years old was dilated cardiomyopathy and graft dysfunction. Before the transplant, Mihr complained a lot about troubled breathing and because of that she was constantly deprived of performing many basic activities of everyday life.

Through the functional assessment it was observed that Mihr had a very good relationship with her mother. She kept her company daily and accompanied her to all her outpatient consultations. Her accounts revealed a harmonious family life, structured and supported by other family members. According to Iris, life after transplant was better because Mihr understood the guidelines related to lifestyle changes as well as the use of medication.

\subsection{Family 3 Interview}

The structural evaluation of family 3 revealed that this was a mononuclear family, composed of Jacinto and his four children; the mother passed away at the age of 35, leaving behind a 3-year-old daughter from her first marriage. Jacinto is 54 years old and works with recycling. Their eldest daughter is a 23-year-old maid/house keeper who lives with her 29-year-old unemployed partner/husband and a 7-year-old daughter who is in Grade $2 / 2^{\text {nd }}$ year of elementary school. The second daughter is 22 years old who only finished up to seventh grade of elementary school, she lives with her 30-year-old partner/husband. She works in a shoe factory and has two daughters, a three and a six-year-old, respectively. The son was 18 years old, living with his father, working as a servant. He only finished grade three of elementary school. Theliel was the fourth child, a 16-year-old who finished the second grade of elementary school; he had an informal job as a bike assembler.

The paternal grandparents died of unknown causes. The maternal grandfather passed away of an unknown cause, and the grandmother did not raise her daughter because she left when the child was three years old (Figure 4).

The development category assessment found that Theliel was born in November 18, 1995 and had a transplant on August 28, 2009, at 14 years of age with the diagnosis of Tetralogy of Fallot congenital heart disease and ventricular dysfunction, indicatives of heart transplant.

The functional category assessment observed that the routine of the family was quite conflictive. Jacinto always accompanied Theliel to consultations, which led him to quit his job. From his accounts it became clear that Theliel did not obey/listen to anybody and did not follow the recommendations of health professionals. Theliel's 


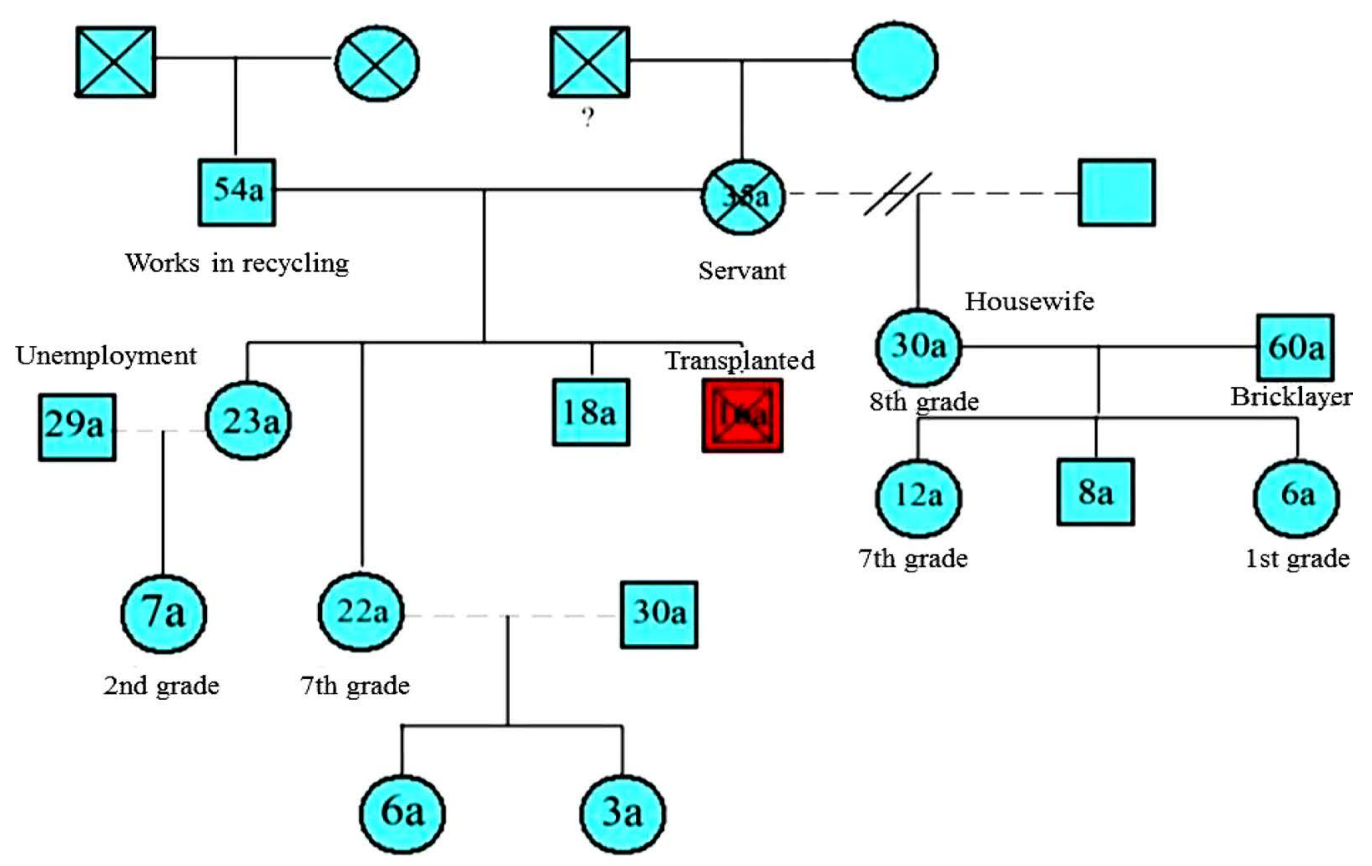

Figure 4. Genogram designed for Amarilis family. Fortaleza, Ceará, Brazil, 2015.

main complaints were that he couldn't play ball or ride a bike because he would quickly feel strong chest pain and fatigue. He also reported feeling unhappy about the imposed diet.

\section{Discussion}

The study reveals how the organization and the structuring of families were in facing the demands of the heart transplant process. Data collection through the genogram enabled nurses to recognize the graphical representation of information about the family, family interactions and its social context. Families 1 and 2 were of equal typologies, represented by a mother, father and children, and the third was different, being composed of only a father and his children.

It was noticed that the families were binuclear or adopted families, since its composition was originated from a second marriage. This family type requires a realignment of roles and relationships, to establish integration between family members among themselves and to maintain the bond between the children of the previous relationship with their father or mother. The family is an important link for those who experience situations of disease/illness, since the provided support is an incentive for continuing treatment and of the well-being of its members [7]. These aspects represent important data for the planning of nursing care by multidisciplinary health teams in hospitals.

In cases of chronic diseases in childhood, the family is even more necessary, being involved in various activities from the simplest to the most complex, such as meal preparation, providing direct care, administration of continuous medication and follow-up consultations to evaluate the state of health [14].

Children that undergo a heart transplant have a long trajectory of risks and challenges, but with the support of multidisciplinary teams and closer ties with other families who share the same situation, there is a decrease in the family's suffering and greater acceptance of the child's condition. Guidance from all those involved in the care of the child/teenager transplant patient are essential, since the whole family structure is shaken after a transplant. In an international study conducted with 37 relatives of renal and pediatric liver transplants, it was found that the main concern of the family caregivers were related to hospital discharge and the care that should be provided at home [15].

Therefore, this highlights the importance of understanding the structure, function and development of the family of pediatric heart transplant patients because it is believed that the relationship between these, the quality of care and the satisfaction of the caregiver, and the child/adolescent transplant patient is directly proportional.

From the data obtained during interviews, families 1,2 and 3 were characterized by members ranging in age 
from 27 to 54 years. It is observed that the family caregivers are relatively young parents and in full active life. Demands from the act of caring can arise from stressors in everyday family dynamics, leading to physical, mental and emotional complications for the caregiver, such as loss of freedom and/or spouse overload/burnout, employment abandonment and reduction/interruption of leisure moments [16]. Such facts could be observed in family 2, as Theliel's father, the primary caregiver, had to quit his job to care for his child heart transplant patient.

A study conducted in Minas Gerais, Brazil, sought to evaluate the quality of life of 46 caregivers to stroke patients, revealing that they have shown a decrease in activities, which represented considerable stress, as many wanted to be enjoying leisure moments with the family [17].

The idealized quality of life after transplant may not always happen. There are cases and accounts from patients who did not report significant life improvement after their transplant due to immunosuppressive therapy and ongoing consultations. This statement is in accordance with a study carried out with kidney transplant patients in Santa Catarina, where it was observed that in the post-transplant, patients endure pain, decreased vitality, changes in their social life and mental health [18].

It is noteworthy mentioning that, despite imbalances caused by a pediatric heart transplant, moments of instability may contribute to the evolution of the family as an institution [19]. This was conveyed by family 2; that by facing all obstacles, it unveiled strengthening, bonding and support among family members, leading to a better quality of life.

With regard to civil status, the two mothers lived with their partners/husbands and the father was a widower. Despite the family support evidenced by the genogram, the literature points out that a chronic situation in children has been linked to increased difficulties in marital relationships, mainly due to constant neglectin giving attention to other family members in favor of the transplant children [20]. Family support in child care is essential, and that must start by promoting information and explanations about what can influence physical and psychological well-being.

Heart transplant patients will go through a long journey, with arriving at the health service being key for creating bonds with health professionals who will follow them in this process. Therefore, the valuable task of involving patients, families and other team members in this action is in the hands of the health team [19].

Low education levels found in participants is a worrying factor, being directly associated with the degree of understanding and following care recommendations given to the transplanted patient's primary caregiver [15].

The education/schooling of the main caregivers must be taken into consideration since it can influence the quality of care, as they need to follow diets, read package inserts of medicines, and understand dosages to provide better care, in addition to the appreciation and awareness of preventing transplant complications [3]. Furthermore, the knowledge about caregivers' education level is essential because they are the ones taking information from the patient and passing them on to the health team. On this point, education in health is related to the learning ability of people, revealing itself as a connecting link between their care and the care of another [1] [21].

Regarding the main occupation, stay at home parents acquired greater distinction, with a total of two mothers and a father who abandoned his job. Of these, all three lived in the countryside. Assessing family income, two of them lived with more than one minimum wage and one with one salary, the pension/benefits of a transplant. A study carried out with a similar population also found low pay among mothers when investigating family income, mostly the only source of income was the child's pension/government package [2].

As for the transplant patients, the average age showed evidence that these were children and teenagers who too soon began to face the complexity of a chronic disease. Two were indicated for transplant for congenital heart disease and one for dilated cardiomyopathy. The authors emphasize that cardiomyopathies are the main causes that lead children to have heart transplants [22] [23].

According to the observation of the presented genograms, it is possible evaluate the family composition, gender of the members, birth order, relations between family members and the intensity of their connections, representing the family of the internal structure and also the extended family of each family origin.

The families of the study showed extended knowledge about their families, stating full details of these. This finding differs with the data obtained in another study, the lack of family ties, with consequent restriction of information about the components of the structure of the family [24].

By analyzing the genograms, the emphasis on care by the maternal figure is noticeable, denoting a greater detachment and excessive need for the availability of mothers to help the children in the process. The importance 
of the role of the family is emphasized, being primordial support before and after the transplant, and their involvement in assistance and rigorous follow-up of the patients, not only burdening the mother.

The highest percentage of women as primary caregivers corroborates with national [16] and international studies [15]. Even with their insertion in the labour market, women have historically played the role of primary caregiver. In general, this activity is socially accepted as natural, and therefore to take care of a family member is one of the roles that women assume in the domestic environment [17].

The strategies applied in group sessions helped to establish a greater link with families in regards to the use of dynamics, of ways of coping/family care of transplants and the entertaining way to conduct the interviews. At this point it is worth noting that during the reports the families were often unprepared to deal with the new reality of their loved one, even though they demonstrated to be strong in caring for the child transplant patient.

In addition, the CFAM intervention with the families used in this study subsidized the framework of the group sessions, since the genogram included the implementation phase of the theoretical framework. At this stage, according to the model in the evaluation of the family, the nurse appropriates its structure to verify effective links between its members to make comparisons and define aspects of internal and external structure, and the sociocultural context.

\section{Conclusions and Clinical Implications}

The family evaluation based on CFAM allowed for learning about the families and brought forth the main aspects of their structure, development and function. From the evaluation, it was possible to reveal some difficulties faced by the investigated families.

The application of the genogram contributed to the acquisition of information about the family, complementing the data obtained during the nursing consultation in outpatient health facility and can support the therapy to be implemented during admission to monitor the patient pre- and post-transplant, adding the family's situational diagnosis to the child's medical record.

Genograms stood out as an instrument that can allow for a refined analysis of family relationships and should be used by the nurse to add important data in the planning of nursing care, but should also be combined with technical/scientific knowledge and observation and communication skills.

It is suggested that the application of theoretical models of intervention in families such as the Calgary model is used to subsidize the implementation of nursing care in pediatric hospitals, as this standard promotes an interactive relationship with the family, making it more participatory in the therapeutic plan established by the nurse.

\section{Limitations and Recommendations for Future Studies}

Although the genogram is used to portray the family relationships, it has the simplification of complex data as a limitation, so caution is needed when using it since the data collected are dynamic, thus may undergo changes over time. Other studies on the same theme are recommended so that the techniques to use the genogram are improved.

\section{Conflict of Interest}

No conflict declared.

\section{Acknowledgements}

We would like to thank all participants in the study.

\section{References}

[1] Araújo, Y.B., Reichert, A.P.S., Vasconcelos, M.G.L. and Collen, N. (2013) Fragility of the Social Network of Families of Children with Chronic Disease. Revista Brasileira de Enfermagem, 66, 675-681. http://dx.doi.org/10.1590/S0034-71672013000500006

[2] Nishimoto, C.L.J. and Duarte, E.D. (2014) Family Organization for the Care of Children with Chronic Conditions, Discharged from the Neonatal Intensive Care Unit. Texto \& Contexto-Enfermagem, 23, 318-327. http://dx.doi.org/10.1590/0104-07072014001330013 
[3] Nicholson, C. (2014) Chronic Heart Failure: Pathophysiology, Diagnosis and Treatment. Nursing Older People, 26, 29-38. http://dx.doi.org/10.7748/nop.26.7.29.e584

[4] Azeka, E., Jatene, M.B., Jatene, I.B., Horowitz, E.S.K., Branco, K.C., Neto, J.D., et al. (2014) I Diretriz Brasileira de Insuficiência Cardíaca e Transplante Cardíaco, no feto, na criança e em adultos com cardiopatia congênita, da Sociedade Brasileira de Cardiologia. Arquivos Brasileiros de Cardiologia, 103, 1-126. http://dx.doi.org/10.5935/abc.2014S005

[5] Nóbrega, V.M., Damasceno, S.S., Rodrigues, P.F., Reichert, A.P.S. and Collet, N. (2013) Atenção à criança com doença crônica na estratégia saúde da família. Cogitare Enfermagem, 18, 57-63. http://dx.doi.org/10.5380/ce.v18i1.28517

[6] Reed-Knight, B., Loiselle, K.A., Devine, K.A., Simons, L.E., Mee, L.L. and Blount, R.L. (2013) Health-Related Quality of Life and Perceived Need for Mental Health Services in Adolescent Solid Organ Transplant Recipients. Journal of Clinical Psychology in Medical Settings, 20, 88-96. http://dx.doi.org/10.1007/s10880-012-9303-6

[7] Radovanovic, C.A.T., Cecilio, H.P.M. and Marcon, S.S. (2013) Avaliação estrutural, desenvolvimental e funcional da família de indivíduos com hipertensão arterial. Revista Gaúcha de Enfermagem, 34, 45-54. http://dx.doi.org/10.1590/S1983-14472013000100006

[8] Majamanda, M.D., Munkhondya, T.E.M., Simbota, M. and Chikalipo, M. (2015) Family Centered Care versus Child Centered Care: The Malawi Context. Health, 7, 741-746. http://dx.doi.org/10.4236/health.2015.76088

[9] Neves, E.T., Cabral, I.E. and Silveira, A. (2013) Family Network of Children with Special Health Needs: Implications for Nursing. Rev Latino-am Enferm, 21, 562-570. http://dx.doi.org/10.1590/S0104-11692013000200013

[10] Figueiredo, M.H.J.S. and Martins, M.M.F.S. (2010) Avaliação familiar: Do Modelo Calgary de Avaliação da Família aos focos da prática de enfermagem. Ciência, Cuidado e Saúde, 9, 552-559. http://dx.doi.org/10.4025/cienccuidsaude.v9i3.12559

[11] Cecilio, H.P.M., Santos, K.S. and Marcon, S.S. (2014) Modelo Calgary de Avaliação da Família: Experiência em um projeto de extensão. Cogitare Enfermagem, 19, 536-544.

[12] Nascimento, L.C., Dantas, I.R., Andrade, R.D. and Mello, D.F. (2014) Genogram and Ecomap: Brazilian Nursing Contributions. Texto \& Contexto-Enfermagem, 23, 211-220. http://dx.doi.org/10.1590/S0104-07072014000100025

[13] Gomes, B.M.R. (2014) Modelo Calgary de Avaliação e Intervenção da Família: Influenciando a prática e a teoria na enfermagem. Revista de Enfermagem UFPE Online, 8, 1-3. http://www.revista.ufpe.br/revistaenfermagem/index.php/revista/article/viewFile/6544/pdf_4989

[14] Santos, A.L., Cecílio, H.P.M., Teston, E.F. and Marcon, S.S. (2012) Knowing the Family Functionality under the View of a Chronically Ill Patient. Texto \& Contexto-Enfermagem, 21, 879-886. http://dx.doi.org/10.1590/S0104-07072012000400019

[15] Lerret, S.M., Weiss, M.E., Stendahl, G., Chapman, S., Neighbors, K., Amsden, K., et al. (2014) Transition from Hospital to Home Following Pediatric Solid Organ Transplant: Qualitative Findings of Parent Experience. Pediatric Transplantation, 18, 527-537. http://dx.doi.org/10.1111/petr.12269

[16] Pinto, J.M.S. and Nations, M.K. (2012) Cuidado e doença crônica: Visão do cuidador familiar no Nordeste brasileiro. Ciência \& Saúde Coletiva, 17, 521-530. http://dx.doi.org/10.1590/S1413-81232012000200025

[17] Santos, N.M.F. and Tavares, D.M.S. (2012) Correlation between Quality of Life and Morbidity of the Caregivers of Elderly Stroke Patients. Revista da Escola de Enfermagem da USP, 46, 960-966. http://dx.doi.org/10.1590/S0080-62342012000400025

[18] Knihs, N.S., Sartori, D.L., Zink, V., Roza, B.A. and Schirmer, J. (2013) A vivência de pacientes que necessitam de transplante renal na espera por um órgão compatível. Texto \& Contexto-Enfermagem, 22, 1160-1168. http://dx.doi.org/10.1590/S0104-07072013000400035

[19] Martins, Q.C.S., Santos, V.S. and Neto, D.P. (2013) Aspects Regarding the Patient/Family and Professionals in the Context of Hematopoietic Stem Cells Transplantation: A Reflective Analysis. Revista de Enfermagem UFPE Online, 7, 6901-6906. http://www.revista.ufpe.br/revistaenfermagem/index.php/revista/article/viewArticle/3321

[20] Nóbrega, V.M., Reichert, A.P.S., Silva, K.L., Coutinho, S.E.D. and Collet, N. (2012) Impositions and Conflicts on the Daily Routine of Families of Children with Chronic Disease. Escola Anna Nery, 16, 781-788. http://dx.doi.org/10.1590/S1414-81452012000400020

[21] Araújo, J.S., Vidal, G.M., Brito, F.N., Gonçalves, D.C.A., Leite, D.K.M., Dutra, C.D.T., et al. (2013) Profile of Caregivers and Difficulties in Elderly Care in the City of Ananindeua, State of Para, Brazil. Revista Brasileira de Geriatria e Gerontologia, 16, 149-158.

[22] Aguiar, M.I.F., Farias, D.R., Pinheiro, M.L., Chaves, E.S., Rolim, I.L.T.P. and Almeida, P.C. (2011) Qualidade de vida de pacientes submetidos ao transplante cardíaco: Aplicação da escala whoqol-bref. Arquivos Brasileiros de Cardiologia, 96, 60-67. http://dx.doi.org/10.1590/S0066-782X2010005000133 
[23] Thrush, P.T. and Hoffman, T.M. (2014) Pediatric Heart Transplantation: Indications and Outcomes in the Current Era. Journal of Thoracic Disease, 6, 1080-1096.

[24] Almeida, A.P.D. (2011) Quando o vínculo é doença: A influência da dinâmica familiar na modalidade de aprendizagem do sujeito. Revista Psicopedagogia, 28, 201-213. 